\title{
OPERATOR INEQUALITIES AMONG ARITHMETIC MEAN, GEOMETRIC MEAN AND HARMONIC MEAN
}

\section{SHIGERU FURUICHI}

Abstract. We give an upper bound for the weighted geometric mean using the weighted arithmetic mean and the weighted harmonic mean. We also give a lower bound for the weighted geometric mean. These inequalities are proven for two invertible positive operators.

Mathematics subject classification (2010): 15A39, 15A45.

Keywords and phrases: Operator inequality, operator mean.

\section{REFERENCES}

[1] F. Kubo And T. Ando, Means of positive operators, Math. Ann., Vol. 264 (1980), pp. 205-224.

[2] T. FURUTA AND M. YANAGIDA, Generalized means and convexity of inversion for positive operators, Amer. Math. Monthly, Vol. 105 (1998), pp. 258-259.

[3] S. Furuichi, On refined Young inequalities and reverse inequalities, J. Math. Ineq., Vol. 5 (2011), pp. 21-31.

[4] S. FurUichi, Refined Young inequalities with Specht's ratio, J. Egypt. Math. Soc., Vol. 20 (2012), pp. $46-49$.

[5] H. Zuo, G. Shi And M. Fujil, Refined Young inequality with Kantrovich constant, J. Math. Ineq., Vol. 5 (2011), pp. 551-556.

[6] M. KRNIĆ, N. LOVRIČEVIĆ AND J. PEČARIĆ, Jensen's operator and applications to mean inequalities for operators in Hilbert space, Bull. Malays. Math. Sci. Soc., Vol. 35 (2012), pp. 1-14.

[7] F. Kittaneh, M. KRnić, N. LovričEvić And J. PeČARIĆ, Improved arithmetic-geometric and Heinz means inequalities for Hilbert space operators, Publ. Math. Debrecen, Vol. 80 (2012), pp. 465 478. 